\title{
Biocatalytic Reductive Amination- Discovery to Commercial Manufacturing applied to Abrocitinib JAK1 inhibitor
}

Rajesh Kumar ( $\square$ rajesh.kumar3@pfizer.com )

Pfizer

Michael Karmilowicz

Pfizer

Dylan Burke

PGS

Michael Burns

Pfizer

Leslie Clark

PGS

Christina Connor

Pfizer

Eric Cordi

Pfizer

Nga Do

Pfizer

Kevin Doyle

Pfizer

Steve Hoagland

Pfizer

Chad Lewis

Pfizer

David Mangan

PGS

Carlos Martinez

Pfizer

Emma McInturff

Pfizer

Kevin Meldrum

Pfizer

Robert Pearson 
Pfizer

Jeremy Steflik

Pfizer

Anil Rane

Pfizer

John Weaver

Pfizer

\section{Keywords:}

Posted Date: February 23rd, 2021

DOI: https://doi.org/10.21203/rs.3.rs-244144/v1

License: (c) This work is licensed under a Creative Commons Attribution 4.0 International License. Read Full License

Version of Record: A version of this preprint was published at Nature Catalysis on September 21st, 2021. See the published version at https://doi.org/10.1038/s41929-021-00671-5. 


\section{Abstract}

The authors have requested that this preprint be removed from Research Square. 